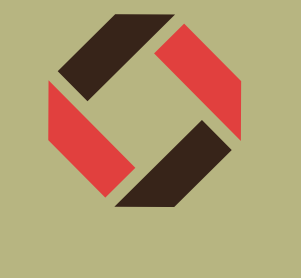

\section{Indigenous Amazonian potteries as early reinforced ceramics}

\section{By Hortense Le Ferrand}

$\mathrm{W}$ hen the Ice Age ended about 12,000 years ago, nomadic foragers began to settle into large villages in prosperous areas around rivers and lakes, domesticating animals and developing agriculture. A few hundred years later, the age of pottery began, providing materials for use with food and crops, as trading goods, and for religious utensils. Each village and local culture developed its own pottery style, with unique combinations of forms, engravings, and colors reflecting mythological narratives and local traditions.

Along the Amazon River in the South American tropical rainforest, indigenous people lived in symbiosis with the environment and made large, rounded ceramic vessels directly from the soil of their settlements. In the floodplains of the Urubu River, upstream of the Amazon, the acidic blackwater deposits, resulting from decaying vegetation, have particularly high amounts of aluminum and iron ions, two elements essential for potteries.

In this region, the multicellular freshwater sponges Drulia uruguayensis-a

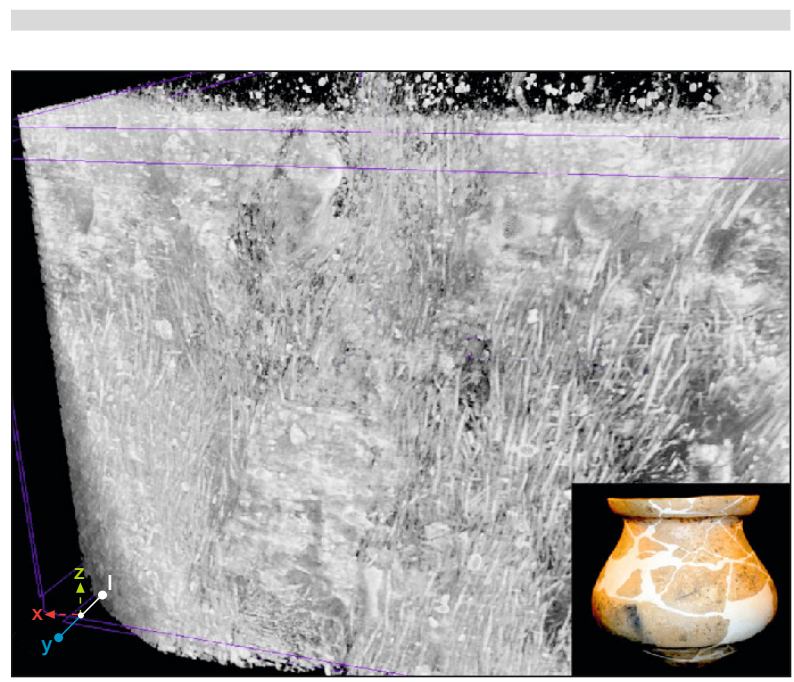

Three-dimensional tomographic reconstruction of potsherds (inset) using synchrotron $\mathrm{x}$-rays showing aligned freshwater sponges' spicules. Photo courtesy of Filipe Natalio. family of Demospongiae — are found as spiky stacks attached to trees, rocks, or grass, waiting for the next flood to spread their gemmules, clusters of embryonic cells. The skeleton of these animals is comprised of microscopic spicules, needle-like structures made of $80-90 \%$ amorphous silica, with the remaining composed essentially of aluminum and iron, with traces of numerous other elements that the sponges filter from the water. The remains of decomposed bodies of these sponges further enrich the soil of the floodplains with their mineral spicules.

Around 2000 years BC, indigenous potters prepared ceramic vessels by mixing raw clay extracted from the floodplain with water and other temper materials. Sand, ashes from wood or bones, crushed old potteries (grog), crushed sponges, and rocks were among the many additives that facilitated the construction of the vessel and improved the resistance to breaking of the pots.

Once the mixture was prepared, water was removed to obtain a malleable solid paste, and all air bubbles were ejected by a succession of slapping, pressing, and turning. They shaped the paste into a rough coil or long rectangle to start building the structure. Coils were stacked while the potters used their fingers to maintain a constant thickness and to erase the interfaces between the coils. The presence of spicules from the sponges' skeletons provided plasticity to the clay as it aligned during the elongation of the coils, whereas the other tempers provided more solidity to prevent the collapse of the structure during mounting.

If the humidity of the tropical rainforest reached $100 \%$, the high temperature of the air and of the hands of the potters could slowly dry the pottery, requiring the addition of water between each coil. More tempers, between $5 \%$ and $10 \%$ of the clay, also helped to keep a steady water content and to avoid large cracks to emerge.

Once the ceramic pot was ready, it was left to dry for several days until the surface had a leather-like consistency. This semi-solidification made it easier to manipulate and to polish using turtle shell scrapers, rocks, or wood. The smooth surface was ideal for engraving symbols or adding decorations.

When the pot was dry, it was fired in an open-air kiln. In these fires, the temperature did not exceed $500-600^{\circ} \mathrm{C}$, so the imperfections in the ceramic and the uncontrolled heating rate did not always lead to the maximum yield. The potters at that time had already experienced that the addition of temper was also beneficial for the outcome of the firing. Bones, sand, and crushed rocks contain calcium phosphates that act as flux at these temperatures and vitrify the final ceramic, increasing its strength but also making it more impermeable and suitable for containing liquids. Fibrous tempers such as the sponges' spicules were also effective in preventing cracks from spreading and breaking the pots. Microcracks were deflected by each spicule encountered, extending the path required before breaking.

Broken potteries were also not wastedthey could be crushed and used as grog to create a new piece. Intimately connected with their environment, the inhabitants of the Amazonia believed in the intertwining and interdependence of all things, exemplified in the fabrication of their potteries.

\section{Further Readings}

1. A.C. Roosevelt, Science 254, 5028 (1991).

2. M.S. Tite, Archaeometry 43, 3 (2001).

3. M.L. Costa, D.C. Kern, A.H.E. Pinto, J.R.T. Souza, Acta Amazon. 34, 375 (2004).

4. F. Natalio, T.P. Corrales, S. Wanka, P. Zaslansky, M. Kappl, H.P. Lima, H.-J. Butt, W. Tremel, Sci. Rep. 5, 13303 (2015).

5. B. Wastiau, Amazon Catalog. The Shaman and the Thought of the Forest (DessinOriginalPlanete, France, 2016). 